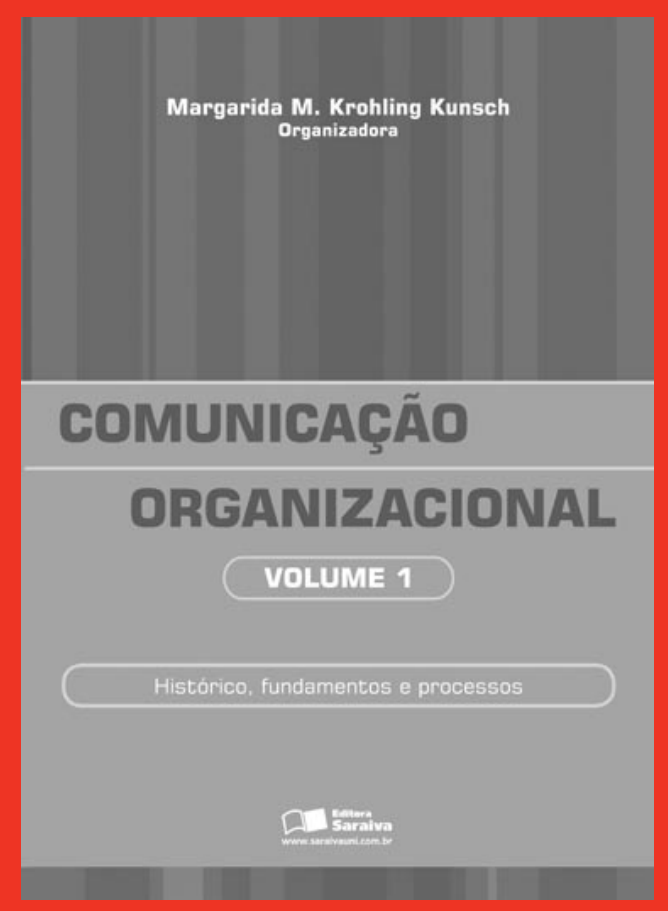

Comunicação organizacional. Vol. 1. Histórico, fundamentos e processos

Margarida M. Krohling Kunsch (Org.)

São Paulo, SP:

Saraiva, 2009

387 páginas

Resenhado por:

Mônica Elisa Dias Pons

- Doutora em Comunicação Social pela Pontifícia Universidade Católica do Rio Grande do Sul (PUCRS-RS)

- Graduada em Relações Públicas pela Universidade Federal de Santa Maria (UFSM)

- Chefe do Departamento de Comunicação Social e Coordenadora do MBA em

Comunicação Empresarial da Universidade dee Santa Cruz do Sul (Unisc)

- Coorganizadora do livro Perspectivas em relações públicas (Edunisc, 2008)

- monica@unisc.br 


\title{
Configuração do arcabouço de uma teoria brasileira de Comunicação Organizacional
}

\author{
The configuration of a Brazilian \\ Organizational Communication theory
}

La configuración del marco de una teoría
brasileña de la Comunicación Organizacional

o cenário atual crê-se que a Comunicação Organizacional represente um
dos alicerces do desenvolvimento da organização. Embora ainda persista
certa resistência no mercado empresarial em relação ao tema, nunca foi tão
relevante e presente estudar, analisar, aplicar, estruturar, interpretar e avaliar
o desenvolvimento de práticas contemporâneas de comunicação no ambiente
interno e externo das organizações.

Esse primeiro volume - Histórico, fundamentos e processos - da coletânea Comunicação organizacional, organizada por Margarida M. Krohling Kunsch, nos oferece uma oportunidade de olhar mais atentamente as questões cotidianas presentes nas organizações em seus processos e fluxos. Dividido em quatro partes e dezessete capítulos, ele nos leva a um delineamento perfeito, ou seja, um caminho de leitura cuidadosamente organizado em torno das temáticas apresentadas em cada bloco. Para dar conta de tamanha variedade de temas, a organizadora lançou mão de um seleto time de investigadores, representantes da diversidade e atualidade das pesquisas realizadas nas universidades brasileiras. De se ressaltar que um projeto coletivo de tal envergadura só podia mesmo ter sido arquitetado e, principalmente, viabilizado por uma estudiosa experiente e com respeitado trânsito no universo da pesquisa acadêmica.

$\mathrm{Na}$ primeira parte, se faz um resgate histórico do nascimento e do desenvolvimento da Comunicação Organizacional no Brasil, ao longo de suas diversas etapas e de seus desdobramentos. Apresenta-se a Associação Brasileira de Comunicação Empresarial (Aberje) e sua contribuição na inserção de um pensamento e de uma prática comunicacionais nas organizações. Debate-se sobre como se concretizam as relações entre ensino e pesquisa no Brasil, especialmente nas áreas de Comunicação Organizacional e Relações Públicas. Dessa forma, leva-se a cabo a tarefa, tão indispensável quanto árdua, de historicizar 
um campo de estudo muitas vezes abordado como eterna e incipiente novidade. Os capítulos dessa primeira parte provam o contrário.

A segunda parte traz reflexões pontuais sobre a Comunicação Organizacional em suas diferentes dimensões e interdependências. Nesse sentido, delineia-se uma grande retrospectiva conceitual de 1950 a 2000, contextualizando a evolução da Comunicação Organizacional, seus paradigmas e suas tendências. Apresenta-se uma perspectiva sistêmico-comunicacional de observação e análise das organizações. Expõe-se um modelo de análise dos processos de Comunicação Organizacional com proposições teóricas da "Escola de Montreal". Analisam-se os estudos da Comunicação Organizacional a partir do paradigma da complexidade (Edgar Morin). Discorre-se sobre a dicotomia entre mundo sistêmico e mundo da vida no contexto das organizações. E, por fim, se perpassa uma diversidade de propostas reflexivas com base em temas presentes no cotidiano das empresas. De forma instigante, os capítulos da segunda parte perguntam, respondem e tornam a nos devolver perguntas do universo das possibilidades teóricas. É a sempre necessária discussão das bases e dos rumos da área de Comunicação Organizacional.

Na terceira parte, nos deparamos com possibilidades de pensar a comunicação estratégica no sistema organizacional, a partir de uma discussão sobre gestão dos processos de implantação de programas de qualidade, enfatizando a importância da harmonia entre discursos e ações organizacionais. Conceitua-se a Comunicação Integrada de Marketing e sua importância na sociedade pósmoderna como recurso diante do volume de informações presentes no dia a dia do consumidor/ cidadão. Analisa-se um tema recorrente da nossa atualidade, o da imagem institucional e de suas implicações, uma questão conceitual importante para a administração dos negócios. Também ficamos conhecendo as possibilidades inerentes a uma comunicação organizacional integrada dentro de empresas que aderem à chamada "economia de comunhão". Por último, mas não menos importante, destaca-se a necessidade de uma articulação mais efetiva entre organizações e territórios, como forma de gerar desenvolvimento sustentável. Essa terceira parte mostra ao leitor que o simples acúmulo de informação não é garantia de sucesso. A solução está na busca do "sentido", só entendido dentro do universo da cultura.

$\mathrm{Na}$ quarta parte, se discute a necessidade de incessante reorganização do contexto comunicacional das organizações em função de uma sociedade em permanente transformação. Nesse sentido, se faz uma reflexão sobre as inovações tecnológicas no campo da Comunicação e sua inserção nos ambientes corporativos, propondo-se um modelo de abordagem estratégica para a Comunicação Digital. Também se tecem considerações sobre novas formas de relacionamento entre as organizações e seus públicos e os possíveis desdobramentos dessas interações. Aborda-se a necessidade de explorar e compreender o potencial comunicativo das novas tecnologias como fator de competitividade. E, para finalizar, insere-se um estimulante artigo acerca das possibilidades da comunicação como 
inteligência empresarial. Essa última parte nos dá a certeza que os desafios que a contemporaneidade nos impõe só podem ser vencidos / entendidos na relação contínua entre teoria e prática.

Difundir a pesquisa sempre foi um desafio para os estudiosos brasileiros, desde a dificuldade de publicar até a de comunicar. Por isso, é com satisfação que vemos uma obra que consegue dar conta dessa tarefa. Ela apresenta o estado da arte da pesquisa em Comunicação Organizacional e em Relações Públicas, de maneira sistematizada e com textos de inequívoco valor. Demonstra que já temos, cada vez mais sólida, uma escola brasileira de estudos da Comunicação Organizacional. Trata-se de um livro que nasce como referência obrigatória de leitura, sendo de valor incomensurável para os profissionais atuantes no campo. 